\title{
THE ROLES OF DHA AND UNDP IN LINKING RELIEF AND DEVELOPMENT ${ }^{1}$
}

\section{Michael Askwith}

\section{INTRODUCTION}

The effective and speedy response by the UN system to emergency situations has long posed particular challenges, as it has indeed to other donors from multilateral, bilateral and non-governmental organizations. Across the range of emergencies, from natural disasters such as hurricanes, floods, and drought, to man-made disasters such as wars and civil conflicts, the UN system, except for WFP for food aid, UNHCR in relation to refugees, and UNICEF for women and children, has traditionally played a modest, though not insignificant role in disaster relief. Recently, its role has increased markedly because of the enhanced political dimensions of disasters caused by the breakdown of systems of governance and of territorial boundaries. They have frequently called for an expensive military presence, as in Somalia, the former Yugoslavia, and most recently in Rwanda.

It has long been recognized that short-term emergency relief can only be a partial solution to the immediate needs of affected populations. Additional arrangements are required, to help these populations restore their lives to the status quo ante, and to establish sustainable long-term followup to short-term shocks.

During the 1980s, the UN Disaster Relief Organization (UNDRO) served as the main UN coordinating body. Its main role was to assist in the identification of immediate needs, and to launch appeals to the international community for emergency relief. Individual UN agencies also organized their own appeals, and provided relief, of which the main sources have been the WFP, UNHCR, UNICEF and WHO.

The United Nations Department of Humanitarian Affairs (DHA) was established in 1992 in an attempt to strengthen the coordination of UN system responses to emergency situations, and to rationalize this under an overall umbrella of humanitarian affairs, thereby bringing together political, relief and development dimensions. Headed by an UnderSecretary-General, with Headquarters in New York, currently Mr Peter Hansen, DHA also has an operational office in Geneva which provides the Secretariat for an Inter-Agency Steering Committe on Humanitarian Affairs.

The United Nations Development Programme (UNDP) maintains a Humanitarian Programme, based in New York. This is responsible for a number of tasks to help UNDP carry out its responsibilities in emergency situations. It manages funds from Special Progamme Resources (SPR) for use in emergency relief and coordination, and corresponding functions described below. It also liaises with Headquarters units of UNDP, and UN agencies on emergency matters, organizes with DHA consultations to improve the operational aspects of the relief to development continuum, and helps DHA to carry out its coordination and resource mobilization mandate.

During 1993, close DHA/UNDP collaboration was under way in Africa (Angola, Djibouti, Eritrea, Ethiopia, Kenya, Liberia, Mozambique, Somalia, and Sudan); Asia (Afghanistan, Armenia, Azerbaijan, Cambodia, Georgia), Europe (Former Yugoslavia), Arab States (Iraq, Lebanon) and the Caribbean (Haiti). In most instances, DHA was represented at the country level by the UNDP Resident Representative or Resident Coordinator, although in Afghanistan, Angola, Cambodia, Former Yugoslavia, Mozambique, Somalia and Sudan, DHA responsibilities were carried out by a separate DHA Coordinator or Director.

\section{AREAS OF COOPERATION BETWEEN DHA AND UNDP IN HUMANITARIAN ASSISTANCE}

DHA and UNDP cooperation in linking relief and development must be viewed in the wider context of its understanding of a 'relief to development continuum'. This involves disaster preparedness and prevention coupled with the organization of immediate relief, and followed by longer term rehabilitation and development programmes for the victims

\footnotetext{
1 Based on a UNDP Humanitarian Programme document 'Cooperation between DHA and UNDP in Humanitarian Assistance' (1994), and a presentation made at the Workshop.
} 
of emergencies, whether displaced persons, vulnerable groups or refugees.

\subsection{Capacity-building for disaster- preparedness and disaster mitigation}

Four main areas of cooperation have been actively pursued in the area of disaster preparedness and mitigation.

First in the area of training, the joint UNDP/DHA Disaster Management Training Programme (DMTP), has trained over 1,000 people in 30 countries through week-long workshops, bringing together UN system and national development practitioners and relief personnel, including from donors and NGOs. Of the countries which have received such training, three quarters have initiated follow-up activities in these areas, including the establishment of United Nations Disaster Management Teams (DMTs). During 1993-4, a programme was underway which included a regional workshop for FrenchSpeaking Africa and 40 individual country workshops in Latin America, the Middle East, Africa and Asia, together with short two day workshops for middle management and senior level headquarters staff, and UNDP Resident Coordinators. In addition , work was on-going on the finalization of a UNDP/ DHA Disaster Management Manual to serve the UN system as a whole. The subject of follow-up to emergencies, and the need to consider and plan for the longer-term reintegration and rehabilitation implications is an essential part of this training.

Second, by General Assembly Resolution 44/236 in December 1989, the 1990 s were designated the International Decade for Natural Disaster Reduction (IDNDR), whose recommended targets by the year 2000 are (a) the preparation of comprehensive national assessments of risks from natural hazards, with these assessments taken into account as an essential component of longer term planning for sustainable development; (b) the preparation of mitigation plans at national and/or local levels, involving long term prevention, prepararedness and community awareness, and finally (c) ready access to global, regional, national and local early warning systems and broad dissemination of warnings. The IDNDR Secretariat is part of the DHA office in Geneva. Resident coordinators/resident representatives are responsible for promoting the objectives of IDNDR at the country level, in conjunction with preparations for the World Conference for the IDNDR in Yokohama in May 1994; for assisting as appropriate in the preparation of country reports and reviews of disaster prevention and preparedness related to sustainable development; and in the organization of DMTP country workshops.

Third, UNDP uses its resources in selected countries to provide technical cooperation in strengthening disaster preparedness and disaster mitigation systems, so as to reduce the vulnerability of populations to disasters, through for instance, projects for reforestation, flood control, low-cost housing, and food security. At the same time, DHA advises governments on the development of programmes and activities to reduce risk and mitigate problems, within the context of national plans and the goals of IDNDR.

Fourth, many natural and man-made disasters can be either prevented or mitigated if an appropriate worldwide early warning system is established. Currently several UN organizations, including UNDP, operate or support early warning systems, programmes or projects. DHA, in cooperation with UN organizations, is developing its capacity to serve as a focal point for the 'systematic pooling, analysis and dissemination of early warning information on natural and other emergencies', and to develop adequate response arrangements; UNDP is responsible for developing and operating country-level, regional or global early warning arrangements, while Resident Representatives and DMTs, in addition to other sources, are responsible for collecting relevant information on possible crisis situations as a first line of the UN system's response to an emergency at the country level.

\subsection{Cooperation in sudden disaster and complex emergency situations}

In the case of sudden disasters and other noncomplex emergencies (e.g.tropical storms, floods, volcanic eruptions, earthquakes, sudden influx of displaced populations, and technoligical disasters), the first line of the UN response consists of the Resident Coordinator/Resident Representative and the inter-agency Disaster Management Team. When appropriate, DHA can dispatch its own staff to assist the DMT in identifying needs for intenational disaster relief assistance, and when necessary coordinating the work of international relief teams at the site of the disaster. DHA can also dispatch relief supplies from its warehouse in Pisa, Italy. Both DHA and UNDP can authorize limited funding 
of up to $\$ 50,000$ per emergency. The Resident Coordinator/Resident Representative keeps DHA informed of disaster needs through regular situation reports, whereupon DHA then launches an appeal to the international community. DHA, when appropriate, channels contributions received from the donor community through the resident coordinator/resident representative.

\subsection{Extended and complex emergencies}

With regard to slow-onset natural disasters (e.g. drought, famine) and most manmade disasters (including aspects of famine), the time frame for relief assistance is of longer duration and support structures within UNDP offices often need to be strengthened. UNDP has established emergency units for coordination and disaster management in six African countries (Angola, Ethiopia, Kenya, Liberia, Mozambique and Sudan), financed by UNDP and bilateral contributions, and in some cases, the establishment of inter-agency teams.

In such circumstances, DHA assists in the organization and formulation of consolidated appeals, at the country level, followed by resource mobilization efforts with donors. During 1993, such appeals were organized under the Special Emergency Programme for the Horn of Africa (SEPHA), which includes Somalia, Ethiopia, and Eritrea, as well as for Kenya, Mozambique, Sudan and Angola.

\subsection{DHA and UNDP's role in linking relief and development}

General Assembly Resolution 46/182, establishing the DHA, states that 'emergency assistance must be provided in ways that will be supportive of recovery and long-term development. Development assistance organizations of the UN system should be involved at an early stage and should collaborate closely with those responsible for emergency relief and recovery within their existing mandates'. It further states that the Under-Secretary-General for Humanitarian Affairs will be responsible for 'actively promoting, in close collaboration with concerned organizations, the smooth transition from relief to rehabilitation and reconstruction as relief operations under his aegis are phased out.'

The UNDP Governing Council, in its decision 92/20 encouraged the Administrator to work closely with the DHA and the relevant UN relief organizations so as to enhance their coordinated approach to the continuum from relief to rehabilitation to recon- struction...and requested him to develop further UNDP capacities to promote the transition from relief to development and to make rapid implementation of reintegration programmes.

UNDP has been active in helping to design longer term development programmes in favour of refugee reintegration and rehabilitation (Eritrea, Ethiopia, Mozambique, Somalia), and, with DHA, in the organization of appeals for resource mobilization. For example, UNDP and DHA worked closely with the Government of Eritrea in preparing the Programme for Refugee Reintegration, and Rehabilitation of Resettlement Areas in Eritrea (PROFERI), and in the organization of a multi-donor process of resource mobilization which brought together the relevant government departments, a wide variety of UN agencies, bilateral and multilateral donors, and nongovernmental organizations. It has also helped countries faced with the challenge of reintegrating refugees, to learn from the experience of the Development Programme for Displaced Populations, Refugees and Returnees (PRODERE) in Central America, through the organization of a study tour, and advisory missions.

UNDP has also been frequently involved in assisting in the reconstruction process in the aftermath of disasters, even when it has not been directly involved in the relief phase, for instance in Guatemala after the earthquake in 1980, the Caribbean after periodic hurricanes, and area development schemes for refugee returnees, etc.

\section{CONCLUSIONS}

The formal mechanisms already exist for the UN system to carry out its normal responsibilities with respect to relief and development. The main issues to be addressed by DHA and UNDP in improving on performance, and in implementing LRD approaches are essentially of a practical nature, for instance;

a The inclusion of contingency frameworks, and provision for disaster prevention measures in the context of overall national plans;

b The need for information and research on the experiences of earlier or on-going national emergencies, their causes, and socio-economic impact, as a basis for the preparation of long-term scenarios for future rehabilitation. This also requires 
an institutional memory, and knowledge of research and evaluations already carried out;

c The need for effective and coordinated planning of national relief to rehabilitation programmes, to provide a framework for donor responses, including through the establishment of government/donor task forces to address the issues; $d$ The need for a sufficient level of resources from donors to address longer-term development needs, and not just short-term emergency ones, and for the development of mechanisms to ensure self-sustaining financing from national sources, without which the full potential of linking relief and development cannot be realized. 